\title{
Cross-Cultural Linguistic Analysis of Persuasive Techniques in Shark Tank
}

\author{
Naimah Ahmed S. Al-Ghamdi (Corresponding author) \\ Assistant professor, Sociolinguistics \\ Dept. of English, Imam Abdulrahman Bin Faisal University \\ P.O. Box 1982, Dammam, Saudi Arabia \\ E-mail: dr.naimah666@gmail.com \\ Rand Alghofaily \\ Dept. of English, Imam Abdulrahman Bin Faisal University \\ P.O. Box 1982, Dammam, Saudi Arabia \\ E-mail: roondi205@gmail.com
}

Received: August 25, 2019 Accepted: September 8, 2019 Published: September 9, 2019

doi:10.5296/ijele.v7i2.15416 URL: https://doi.org/10.5296/ijele.v7i2.15416

\begin{abstract}
The present study evaluates the application of William McGuire's Model of persuasion (1968) on Talk Shows from a cross-cultural view. Selected episodes from "Shark Tank" show in its two versions (the American and the Saudi) are transcribed and analyzed to identify the persuasive steps and techniques used by the participants in order to examine how persuasion works in the two different cultures. Results show that McGuire's model was 50\%applied in the American version. Also, the Americans' style of persuasion was characterized by low context meaning, direct speech, linear themes, formal language, verbal techniques oriented, display feelings and creative thinking. On the other hand, McGuire's model of persuasion was $25 \%$ applied in the Saudi version. The Saudis' style of persuasion was characterized by high context meaning, indirect speech, non-linear themes, informal language, nonverbal techniques, partly conceals feelings and Simi creative thinking.
\end{abstract}

Keywords: Talk show, persuasion, argument, qualitative research, Saudi speech society 


\section{Introduction}

Persuasion serves human purposes in all situations, where people try to influence the attitudes, feelings, beliefs, and the behaviors of others (Burgoon \& Miller, 1985). In today's societies, persuasion has become a major linguistic tool for resolving and making decisions allowing, therefore, for effective participation in social life (Jaradat, 1999).

As a basic element in language use, persuasion has received much attention from philosophers and researchers in the fields of social sciences, humanities, and linguistics. The process of persuasion, in general, and the techniques of persuasion, in particular, have been one of the central issues of sociolinguistic and discourse analysis as fields of study. A number of studies on persuasion suggests that the process is primarily and essentially a social act (Burgoon \& Miller, 1985; Sandell, 1977; Kelman, 1958). Therefore, sociolinguistics tries to examine various different techniques of persuasion used in different languages, and how these techniques differ from one culture to another, and from one person to another in the same culture. In order to examine persuasion as a sociolinguistic phenomenon, it is important to establish clearly what is meant by the term. In an article entitled 'persuasion', Miller (1987:451) defines the term as follows:

The term 'persuasion' refers to situations where attempts are made to modify behavior by symbolic transactions (messages) that are sometimes but not always, linked with coercive force (indirectly coercive) and that appeal to the reason and emotions of the intended persuadee(s).

This study aims to look at persuasion from a cross-cultural perspective and to examine the six steps of McGuire's Model of persuasion used by the participants in "Shark Tank" reality show in both American and Saudi versions. Also, it aims to identify persuasive techniques used by the participants and the (linguistic and nonlinguistic) differences between the two versions.

The "Shark Tank" is a reality TV show that was displayed in 2015 on ABC that features a panel of business executives and investors (called 'Sharks') who consider offers and listen to pitches from small business owners seeking funding for their business or products. The Saudi version of this show titled "Thdi:Alhwa:mi:r" which is displayed on Rotana Khalejia channel, 2018.

\section{Statement of the Problem}

Persuasion is considered to be a social process that illustrates the ability to use social understanding in everyday contexts. Language and culture play a central role in the process of persuasion. Hence, the researcher has noticed different persuasion strategies and techniques while watching the Shark Tank show in its two versions (the American and the Saudi). The aim of this current research is to apply William McGuire's Model of persuasion to Talk Shows by utilizing a qualitative content analysis techniques. Specifically, this paper aims to discover and identify the steps of persuasion used in a given social context, which is the Shark Tank show in both versions the American and the Saudi.

In addition, an attempt will be made to determine the techniques used by the participants and 
the sociolinguistic differences between the two cultures as regards to persuasion.

\section{Importance of the Study}

The importance of this study lies in the fact that it provides a descriptive account of persuasion as applied to William McGuire's Model. Moreover, the findings of this study will contribute to our understanding of ways persuasion is used in a social context and to what extent culture has an influence on persuasion techniques and strategies.

\section{Objectives of the Study}

The main objectives behind conducting this study are:

To evaluate William McGuire's Model of persuasion on "Shark Tank" show.

To explore persuasion steps and techniques as used by participants in "Shark - Tank" show.

To investigate the linguistic and non-linguistic differences used by the participants in the two versions of the show (American and Saudi culture).

\section{Questions of the Study}

This study tries to answer the following research questions:

How William McGuire's Model of persuasion is applied to "Shark Tank" show?

What are the strategies and techniques used by the participants in "Shark Tank" show?

What are the linguistic and non-linguistics differences employed by the participants in the two versions of the show (American and Saudi culture)?

\section{Limitations of the Study}

The sample of this study is concerned with the steps of persuasion that are used by the participants in "Shark Tank" show. Moreover, the study examines the persuasion techniques of both men and women participants that they use to persuade the judges (Sharks). This study focuses on two versions of "Shark Tank" show, the American and the Saudi version. The study concentrates on season 6 (episode 14) of the American version "Shark Tank "show in 2015. Also, it concentrates on season 2 (episode 17) of the Saudi version "Thdi:Alhwa:mi:r" show that was displayed in 2018.

\section{Theoretical Frame Work}

This study adopted William McGuire's Model of persuasion (1968) to examine the process of persuasion and to explore different techniques used by participants in "Shark Tank" show as related to each step of the theory. According to McGuire's Model, the process of persuasion is broken down into six sequential steps which are exposure, attention, comprehension, acceptance, retention, action. Exposure: how the persuasive message is presented. Attention: the audience's (judges') attention is very important for persuasion, they cannot be persuaded by message they ignore. There are many techniques and strategies (verbal, nonverbal) used to pay attention in different situations. Comprehension: the audience (judges) must understand 


\section{Macrothink}

the message to affect their attitudes (knowing your audience is a good start). Acceptance: the audience (judges) agree the message. Retention: the message is more likely to be retained, if the listener is interested in. So, the message must be interesting to achieve success. Action: the audience (judges) change their opinion and perception toward the persuasive message. The measure of persuasive success is listener's motivations.

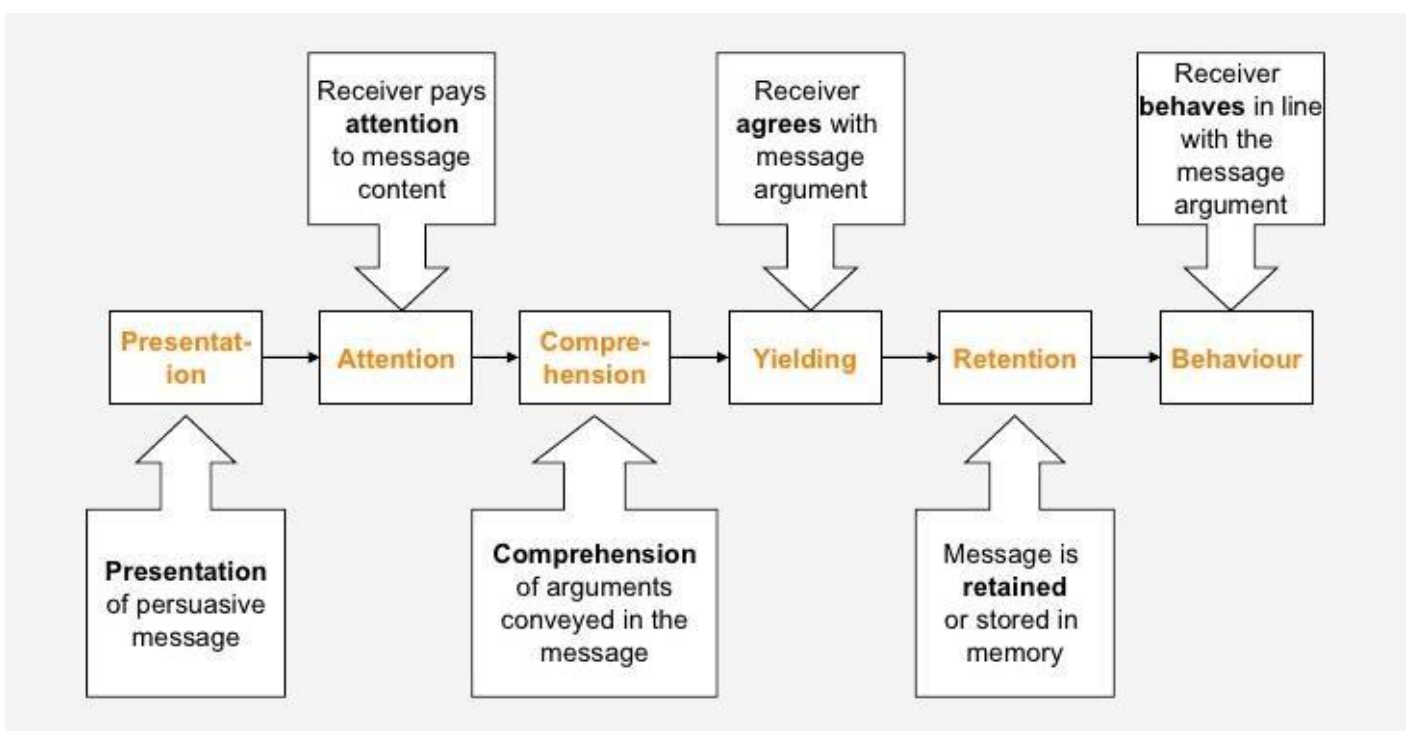

Figure 1. McGuire's Model of persuasion. Source: Dahl, Stepan. (2007).

\subsection{Operating Definitions}

There are some significant terms that are used throughout the study. The following are the operating detentions of these terms:

- Persuasion: Persuasion is defined as "human communication that is designed to influence others by modifying their beliefs, values, or attitudes" (Simons, 1976, p. 21).

- Qualitative Research is a wide range of scientific method of observation to gather and analyze non-numerical data. Methods of qualitative research include observation, open-ended surveys, interviews focus groups, and content analysis of audio, visual and textual materials.

- Shark Tank: is a reality TV show that receives participants (from entrepreneurs and small business owners) to present their products and business to the Sharks who are inventors and self-made millionaire and billionaires. They listen to the participants and give them offers.

\subsection{Histomography of Talk Show Programs}

Reality TV is a crossbred genre that is continually shifting and developing. It was initially 
understood to present everyday life as enjoyment. However, many modern shows place participants in highly constructed situations. Current reality TV involves presenting a range of very structured scenarios, heavily edited to provide audience with entertainment and enjoyable time (Kirkbie Kendal, 2012).

"Shark Tank" is considered as a reality TV show that displays on ABC in 2015. Shark Tank shows entrepreneurs and small business owners as they present business presentations to five investors and business executives ("Sharks"). Then they choose whether to invest as business partners. So, participants must be persuasive to win the challenge. The cast of ABC's Shark Tank is a group of investors and wealthy businessmen and businesswoman, (Mark Cuban, Barbara Corcoran, Lori Greiner, Robert Herjavec, Daymond John and Kevin O'Leary). On the other hand, the Saudi version of this show that called "Thdi: Alhwa:mi:r" is displayed on Rotana Khalejia channel in 2018. The Sharks in the Saudi version are Ali Othaim, Mkarem Butrgy, Nayef AlQhatani, Maha Taiba, Fares alRashid, and Samer AlKurdi.

\section{Literature Review}

In this section, major aspects related to the phenomenon of persuasion are reviewed. In fact, the literature on persuasion is not limited to one field of study. Rather the study of persuasion has been central in the fields of philosophy, social science, psychology and sociolinguistics.

Scholars have defined persuasion in different ways. Perloff (2003) defined persuasion as "a symbolic process in which communicators try to convince other people to change their attitudes or behavior regarding an issue through the transmission of a message, in an atmosphere of free choice" (p.8). Moreover, the author explained five features of persuasion:

(1) Persuasion is a symbolic process, (2) persuasion involves an attempt to influence, (3) people persuade themselves, (4) persuasion involves the transmission of a message, and (5) persuasion requires free choice.

In light of the Perloff's discussion, the researcher define persuasion as the process of changing the attitude or behavior of a person, by using specific strategies to persuade audiences.

According to Jaradat (1999), the study of persuasion can be classified into five major groups. The first group of studies focuses on the definition of persuasion and how it is viewed. The second group studies try to explore the relation between process of persuasion and communication, emotions, and debate, on the other hand. The third group of studies deals mainly with the importance of persuasion in modern life whether for the individuals or the society as a whole. The fourth group of studies deals with the strategies and techniques of persuasion ranging from attitude formation to attitude change and behavioral at change. The fifth group studies attempt to examine the strategies employed in persuasion as: repetition, rhetorical questions, emotion, and statistics.

AlKhatib (2009), on the other hand, argued that previous studies on persuasion have shown that persuasion can be achieved by three techniques, and if the three techniques are utilized at once, persuasiveness will be very effective. In the first technique, the persuaders can appeal 
to their audience by their trustworthiness, and by trying to convince them that he or she is reliable and trustworthy. In the second technique, the persuader can attempt to persuade by using argument and stating his opinion logically to the audience. The persuader then supports his argument by giving several convincing reasons for the arguments made. In the third technique, the persuader can appeal to the audience by an emotional way; the focus here not to intellect but to trigger the audience's feelings.

Persuasion theories have provided a wealth of information detailing when and how people are persuaded. Brown (1963) mentioned many techniques of persuasion used in the formal situations, such as: repetition, selection, assertion, the appeal to authority, and the substitutions of name.

One aspect of persuasion process deals with the nature and characteristics of culture. Orji (2016) studied the persuasive strategies and how they vary from one culture to another. Orji confirmed that some strategies are more suitable in persuading one culture than the other culture. Moreover, some strategies are more persuasive overall and can influence both participants from both cultures. Accordingly, this study aims to better understand how persuasive messages work in a social persuasive context.

\section{Methodology and Data Collection}

This study has a theoretical framework based on William McGuire's Model of persuasion that is applied on two episodes of "Shark Tank" show (American and Saudi versions). The approach of this study is qualitative content analysis. Content analysis is a research methodology for studying and analyzing documents and communication artifacts, which might be texts, pictures, audio or video (Berg, 2014). To address the study questions, the researcher has decided that the most appropriate tool of analysis would be a thematic analysis. Thematic analysis, as a qualitative tool, is the process of identifying, analyzing and classifying patterns or themes within qualitative data. The data for this study was collected from a reality TV show called Shark Tank. Two episodes, from two versions of the show, were chosen randomly, to serve as a content for this study. The first episode was taking from the American version of the show (Shark Tank show: season 6, episode 14). The second episode was taking from the Saudi version of the show (Thdi: Alhwa:mi:r show: season 2, episode 14).

Hence, data analysis applied in this study includes the following stages:

- Becoming familiar with the data (transcription) $\rightarrow$

- Generating initial codes (coding, data reduction, data complication)

- Searching for themes (analyzing codes, identifying potential themes)

- Reviewing the themes (Refining and reviewing themes, patterns, themes validity and matching)

- Defining and naming themes (depth analysis of themes, naming and explaining major themes) 
- Describing and reporting the results

\section{Analysis and Discussion of Data}

The speech and techniques used by the eight participants of both versions are clearly shown in appendix A.

Analyzing the data will be by answering the study questions.

\section{Q1: How William McGuire's Model of persuasion is applied to "Shark Tank" show?}

The study reveals that the McGuire's six steps of persuasion was not fully applied by all the participants of the study sample as shown in Table 1 . The data analysis showed that the most implemented steps (in both versions) were Exposure, Attention, and Comprehension. Whereas the least implemented steps are Retention and Action. The forth step Acceptance was implemented equally. The first three steps (Exposure, Attention, and Comprehension) were achieved by all the eight participants of the two versions (\%100). The Forth step (Acceptance) was achieved by three American participants and one Saudi participant (\%50). The two last steps (Retention and Action) were achieved by three participants, two from the American version and only one participant from the Saudi version (\%37). So, the data analysis found that two participants (50\%) of the American version applied all the persuasive steps, while only one participant $(25 \%)$ of the Saudi version applied them. The rest of the participants who are two from the American version (50\%) and three from the Saudi version $(75 \%)$ did not achieve all the steps, and failed in applying them.

One of the interesting findings in this study is that the supportive techniques could save the persuasion process without going through all the steps. In the American version, participant one succeeded in the persuasion process without achieving all the steps. She (participant one) achieved the fourth step "acceptance" from the judges (Sharks) after using a supportive technique (sad emotions).

Table 1. Percentage of achieved steps by participants

\begin{tabular}{|c|c|c|c|c|c|c|c|c|c|c|}
\hline & \multicolumn{9}{|c|}{ American version } & \multicolumn{7}{|c|}{ Saudi version } & \multicolumn{1}{|c|}{} \\
\hline Steps & P1 & P2 & P3 & P4 & P5 & P6 & P7 & P8 & Total & $\%$ \\
\hline Exposure & + & + & + & + & + & + & + & + & 8 & $100 \%$ \\
\hline Attention & + & + & + & + & + & + & + & + & 8 & $100 \%$ \\
\hline Comprehension & + & + & + & + & + & + & + & + & 8 & $100 \%$ \\
\hline Acceptance & + & - & $\times$ & - & + & $\times$ & $\times$ & $\times$ & 4 & $50 \%$ \\
\hline Retention & $\times$ & - & $\times$ & - & + & $\times$ & $\times$ & $\times$ & 3 & $37 \%$ \\
\hline Action & $\times$ & - & $\times$ & - & + & $\times$ & $\times$ & $\times$ & 3 & $37 \%$ \\
\hline
\end{tabular}

- The step is applied to two or more judges (Sharks)

- The step is applied to only one judge (Shark)

- The step is not achieved

Q 2: What are the strategies and techniques used by the participants in "Shark Tank" show? 
Table 2. Techniques used by American participants

\begin{tabular}{|c|c|c|c|c|c|c|}
\hline & Technique & P1 & $\mathbf{P 2}$ & P3 & P4 & Total \\
\hline \multirow{12}{*}{$\begin{array}{c}\text { Verbal } \\
\text { language }\end{array}$} & Tone & $\sqrt{ }$ & $\sqrt{ }$ & $\sqrt{ }$ & - & $\% \mathbf{1 0 0}$ \\
\hline & $\begin{array}{c}\text { Rhetorical } \\
\text { quesions }\end{array}$ & $\sqrt{ }$ & - & $\sqrt{ }$ & - & $\% \mathbf{5 0}$ \\
\hline & Repetition & $\sqrt{ }$ & $\sqrt{ }$ & $\sqrt{ }$ & $\sqrt{ }$ & $\% 100$ \\
\hline & Weasel words & - & $\sqrt{ }$ & $\sqrt{ }$ & - & $\% \mathbf{5 0}$ \\
\hline & Jargon & - & $\sqrt{ }$ & $\sqrt{ }$ & - & $\% \mathbf{5 0}$ \\
\hline & Slogan & $\sqrt{ }$ & - & - & $\sqrt{ }$ & $\% \mathbf{5 0}$ \\
\hline & Alliteration & - & $\sqrt{ }$ & - & $\sqrt{ }$ & $\% \mathbf{5 0}$ \\
\hline & Connotation & $\sqrt{ }$ & $\sqrt{ }$ & $\sqrt{ }$ & $\sqrt{ }$ & $\% 100$ \\
\hline & Metaphor & $\sqrt{ }$ & $\sqrt{ }$ & - & - & $\% \mathbf{5 0}$ \\
\hline & Simile & - & $\sqrt{ }$ & $\sqrt{ }$ & - & $\% \mathbf{5 0}$ \\
\hline & Exaggeration & $\sqrt{ }$ & $\sqrt{ }$ & $\sqrt{ }$ & $\sqrt{ }$ & $\% 100$ \\
\hline & Statistic & $\sqrt{ }$ & $\sqrt{ }$ & $\sqrt{ }$ & - & $\% 75$ \\
\hline & Using hands & $\sqrt{ }$ & $\sqrt{ }$ & $\sqrt{ }$ & $\sqrt{ }$ & $\% 100$ \\
\hline & Hand pointing & $\sqrt{ }$ & $\sqrt{ }$ & - & - & $\% 75$ \\
\hline & Moving & - & - & - & $\sqrt{ }$ & $\% 25$ \\
\hline & Eyebrows mov & $\sqrt{ }$ & $\sqrt{ }$ & - & - & $\% 75$ \\
\hline & Eye movement & $\sqrt{ }$ & $\sqrt{ }$ & $\sqrt{ }$ & $\sqrt{ }$ & $\% 100$ \\
\hline & Eye contact & $\sqrt{ }$ & $\sqrt{ }$ & $\sqrt{ }$ & $\sqrt{ }$ & $\% 100$ \\
\hline & Smiling & $\sqrt{ }$ & $\sqrt{ }$ & $\sqrt{ }$ & $\sqrt{ }$ & $\% 100$ \\
\hline & Humor & $\sqrt{ }$ & $\sqrt{ }$ & - & $\sqrt{ }$ & $\% 75$ \\
\hline & Enthusiasm & $\sqrt{ }$ & $\sqrt{ }$ & - & $\sqrt{ }$ & $\% 75$ \\
\hline & Self confidence & $\sqrt{ }$ & - & $\sqrt{ }$ & $\sqrt{ }$ & $\% 75$ \\
\hline & Total & 17 & 17 & 13 & 15 & \\
\hline
\end{tabular}




\begin{tabular}{|c|c|c|c|c|}
\hline $\begin{array}{l}\text { Supportive } \\
\text { Techniques }\end{array}$ & $\begin{array}{l}\text {-simultaneous } \\
\text {-Giving } \\
\text { examples } \\
\text { (testing } \\
\text { cookies) } \\
\text {-sharing } \\
\text { background } \\
\text {-sharing sad } \\
\text { emotions. } \\
\text { crying } \\
\text {-Logo } \\
\text {-logo }\end{array}$ & $\begin{array}{l}\text {-presenting the } \\
\text { problem(bottle) } \\
\text {-presenting the } \\
\text { product } \\
\text {-experience the } \\
\text { product in } \\
\text { front of the } \\
\text { audience. } \\
\text {--giving } \\
\text { samples }\end{array}$ & $\begin{array}{l}\text {-Anecdotes } \\
\text {-Bringing } \\
\text { models } \\
\text { wearing the } \\
\text { product } \\
\text { (appearance) } \\
\text {-Giving } \\
\text { samples } \\
\text {-Testimonial }\end{array}$ & $\begin{array}{l}\text {-Testing the } \\
\text { product in } \\
\text { front of the } \\
\text { audience. } \\
\text {-Wearing the } \\
\text { product. } \\
\text { Appearance } \\
\text {-Giving } \\
\text { samples(gifts) }\end{array}$ \\
\hline
\end{tabular}

From table 2 we can note that the most used of verbal techniques by all the American participants are tone, repetition, connotation, exaggeration (100\%). The second most used technique is statistic i.e. facts include numbers (75\%). Some techniques were used by half of the participants which are slogan (i.e. short phrase to identify a product), weasel words (i.e. phrases to persuade without evidence), and alliteration (50\%). The least used techniques are rhetorical questions, jargon, and simile (25\%).

On the other hand, the most used of nonverbal techniques were using hands, eye movement, eye contact, and smiling (100\%). The second most used techniques were eye brows movement, humor, enthusiasm and self-confidence (75\%). Moreover, Hand pointing technique is used by the half of the participants $(50 \%)$. The least used of nonverbal techniques is moving $(25 \%)$.

It is interesting to note that the participants did not depend only on the verbal and nonverbal techniques in the persuasion process. They used another techniques which the researcher call it (supportive techniques) to influence the judgments and to achieve persuasion. The supportive techniques as the researcher defined are the techniques that are neither verbal nor nonverbal, and help the participants in the persuasion process. So, the participant used different and special techniques in different ways during the persuasion process. The data analysis showed that some supportive techniques relied on the emotional aspect like sharing sad emotions, sharing background, and anecdotes (i.e. sharing personal story). Other techniques relied on the appearance like using logo, wearing the product, and bringing models.

Table 3. Techniques used by Saudi participants

\begin{tabular}{|c|c|c|c|c|c|c|}
\hline & Technique & P1 & P2 & P3 & P4 & Total \\
\hline \multirow{3}{*}{$\begin{array}{c}\text { Verbal } \\
\text { language }\end{array}$} & Tone & $\begin{array}{c}\text { Rhetorical } \\
\text { quesions }\end{array}$ & - & - & $\sqrt{ }$ & - \\
\cline { 2 - 7 } & Repetition & $\sqrt{ }$ & - & - & - & $\%$ \\
\cline { 2 - 7 } & & $\sqrt{ }$ & $\sqrt{ }$ & $\sqrt{ }$ & $\% 100$ \\
\hline
\end{tabular}




\begin{tabular}{|c|c|c|c|c|c|c|}
\hline & Weasel words & $\sqrt{ }$ & - & $\sqrt{ }$ & - & $\% 50$ \\
\hline & Jargon & $\sqrt{ }$ & - & - & - & $\% 25$ \\
\hline & Slogan & $\sqrt{ }$ & - & - & - & $\% 25$ \\
\hline & Alliteration & - & $\sqrt{ }$ & - & $\sqrt{ }$ & $\% 25$ \\
\hline & Connotation & - & $\sqrt{ }$ & $\sqrt{ }$ & $\sqrt{ }$ & $\% 50$ \\
\hline & Metaphor & - & - & - & - & $\% 75$ \\
\hline & Simile & - & $\sqrt{ }$ & - & - & $\% 0$ \\
\hline & Exaggeration & $\sqrt{ }$ & $\sqrt{ }$ & $\sqrt{ }$ & - & $\% 25$ \\
\hline & Statistic & $\sqrt{ }$ & - & $\sqrt{ }$ & $\sqrt{ }$ & $\% 75$ \\
\hline & Using hands & $\sqrt{ }$ & $\sqrt{ }$ & $\sqrt{ }$ & $\sqrt{ }$ & $\% 75$ \\
\hline & Hand & $\sqrt{ }$ & - & $\sqrt{ }$ & - & $\% 100$ \\
\hline & Moving & $\sqrt{ }$ & - & - & - & $\% 25$ \\
\hline & Eyebrows & $\sqrt{ }$ & - & $\sqrt{ }$ & - & $\% 50$ \\
\hline & Eye & $\sqrt{ }$ & $\sqrt{ }$ & $\sqrt{ }$ & $\sqrt{ }$ & $\% 100$ \\
\hline & Eye contact & $\sqrt{ }$ & $\sqrt{ }$ & $\sqrt{ }$ & $\sqrt{ }$ & $\% 100$ \\
\hline & Smiling & $\sqrt{ }$ & $\sqrt{ }$ & - & - & $\% 50$ \\
\hline & Humor & $\sqrt{ }$ & - & - & - & $\% 25$ \\
\hline & Enthusiasm & $\sqrt{ }$ & $\sqrt{ }$ & $\sqrt{ }$ & - & $\% 75$ \\
\hline & $\begin{array}{c}\text { Self } \\
\text { confidence }\end{array}$ & $\sqrt{ }$ & - & $\sqrt{ }$ & - & $\% 50$ \\
\hline & Total & 17 & 10 & 14 & 8 & \\
\hline $\begin{array}{l}\text { Supportive } \\
\text { Techniques }\end{array}$ & & $\begin{array}{l}\text {-Giving } \\
\text { examples } \\
\text { (tasting } \\
\text { ice-cream with } \\
\text { many flavours) } \\
\text {-Bringing } \\
\text { ice-cream truck } \\
\text {-Anecdotes } \\
\text {-logo } \\
\text {-Reasoning } \\
\text {-Code-switching }\end{array}$ & $\begin{array}{l}\text {-Sharing } \\
\text { background } \\
\text {-Lego } \\
\text {-Code-switching }\end{array}$ & $\begin{array}{l}\text {-Anecdotes } \\
\text {-Sport wear } \\
\text { (appearance) } \\
\text {-Giving } \\
\text { samples } \\
\text {-Evidence } \\
\text { (videos and } \\
\text { pictures) } \\
\text {-Testimonial }\end{array}$ & $\begin{array}{l}\text {-Giving } \\
\text { samples (by } \\
\text { giving } \\
\text { bulletins) } \\
\text {-Appearance } \\
\text { of product } \\
\text { content }\end{array}$ & \\
\hline
\end{tabular}


As shown in table.3, the Saudi participants used both verbal and nonverbal techniques during the persuasion process. Starting with the verbal techniques, the most used technique was repetition $(100 \%)$. The second most used techniques were connotation, exaggeration, and statistics $(75 \%)$. The techniques that were used by half the participants are tone, weasel words, alliteration, and slogan (50\%). The least used techniques were jargon, and simile (25\%). Unexpectedly, there were some techniques that have not used by any participant like rhetorical questions and metaphor $(0 \%)$.

On the other hand, the most used of nonverbal techniques in the Saudi version were using hands, eye movement, and eye contact (100\%). The second most used technique was enthusiasm (75\%). The techniques that were used by half of the participants are hand pointing, eye brows movement, self-confidence and smiling (50\%). The least used techniques were moving and humor $(25 \%)$.

The data analysis showed that the Saudi participants' use of the techniques were not limited on the verbal and nonverbal techniques. They used supportive techniques to achieve more success in the persuasion process. Some supportive techniques relied on appearance like logo, sportswear and the appearance of the product content. Other techniques relied on the emotional aspect like sharing background, and anecdotes. Moreover, there were supportive techniques which based on language like Code-Switching from Arabic to English.

\section{Q3: What are the linguistic and non-linguistic differences employed by the participants in the two versions of the show (American and Saudi culture)?}

In this study, the researcher makes a cross- cultural linguistic analysis between the American and Saudi version. So, the data analysis showed the linguistic and nonlinguistic differences between the participants of the two cultures. The American participants relied on the linguistic techniques more than the nonlinguistic techniques. However, the Arabic participants used the nonlinguistic (nonverbal) techniques more than the linguistic (verbal) techniques. Starting with the linguistic differences, the American participants relied on the tone, rhetorical question, connotation, and exaggeration (100\%). On the other hand, the Saudi participants relied on repetition only (100\%). The American participants used jargon, slogan, and simile more than the Saudi participants. Moreover, there are some linguistic (verbal) techniques were only used by the American participants and were not used by the Saudi participants, as metaphor and rhetorical questions.

Regarding the nonlinguistic techniques (nonverbal), the American participants relied on using hands, eye movement, eye contact, and smiling. On the other hand, the Saudi participants relied on using hands, eye contact, and eye movement. Hand pointing, eye brows movement, smiling, humor and self-confidence were used more by the American participants. Moreover, the data analysis revealed that there are some techniques used equally by the two versions as enthusiasm and moving.

The study also revealed other interesting aspects which characterize each culture with regard to the persuasion context. While the style of persuasion among American participants is characterized by low context, direct speech, linear themes, formal language, display feelings, 
and creative thinking. The style of Saudi participants is on the contrary. The following table summarizes these differences between the two cultures:

Table 4. A comparison between American and Saudi culture

\begin{tabular}{|c|c|}
\hline American culture & Saudi culture \\
\hline $\begin{array}{l}\text {-Low context meaning (messaging in } \\
\text { meaning) } \\
\text { - Direct speech (clear) } \\
\text {-Linear themes (One theme; organized with } \\
\text { beginning and end) } \\
\text {-Formal language } \\
\text {-Displays feelings } \\
\text {-Creative thinking }\end{array}$ & $\begin{array}{l}\text {-High context (meaning in context) } \\
\text {-Indirect (ambiguous) } \\
\text {-Non-Linear (multi themes; not organized) } \\
\text {-Informal } \\
\text {-Partly conceals feelings } \\
\text {-Simi creative thinking }\end{array}$ \\
\hline
\end{tabular}

This study is in line with "The Lewis Culture Model", 1990. Lewis segments national countries in relation to three categories Linear-active, Multi-active and Reactive. As shown in Figure. 2 below the American culture falls under the linear-active group while the Saudi culture refers to the multi-active.

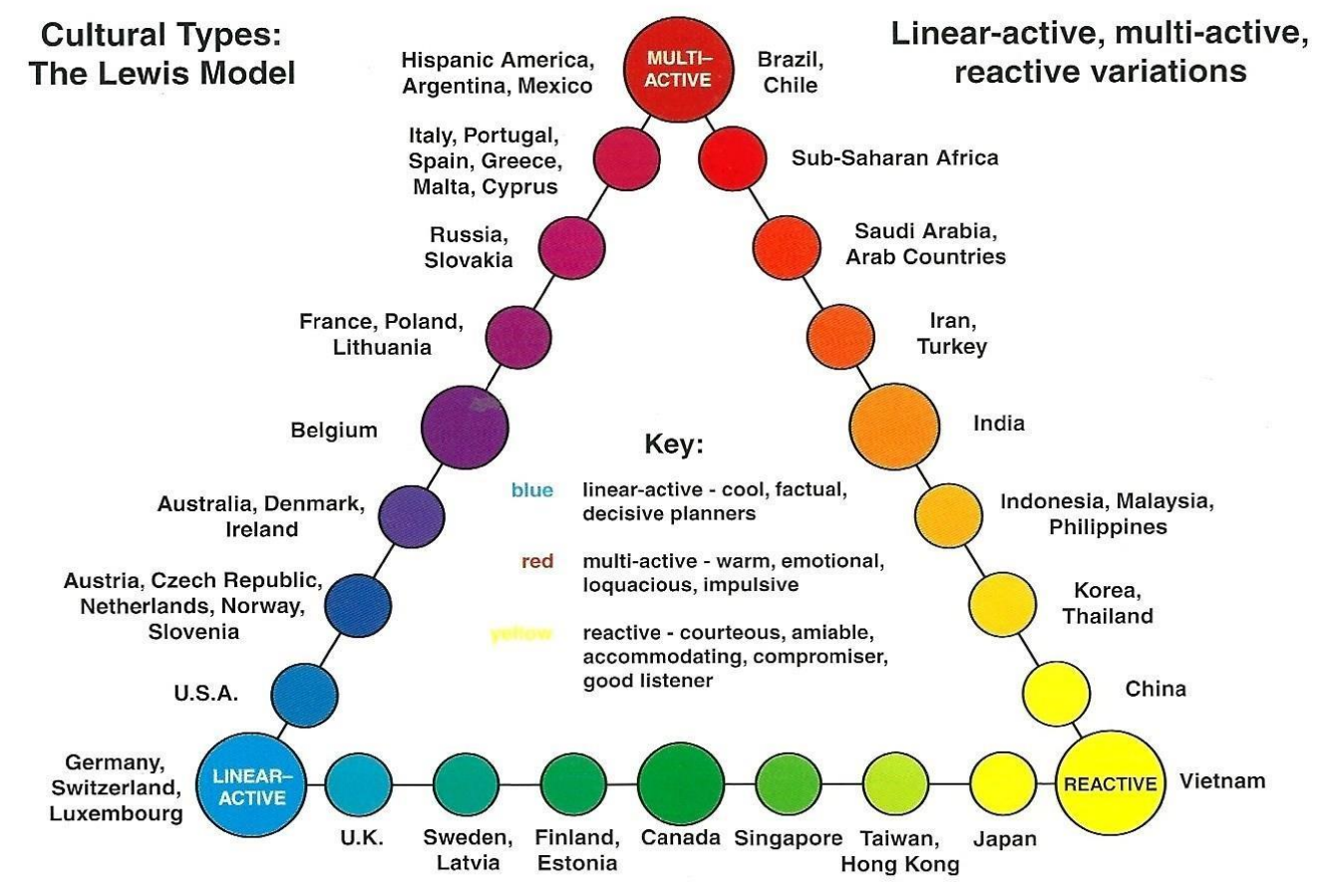

Figure 2. Lewis Model. Source: Admin, C. 2015

The linear active group (included American culture) are people who talk half the time, do one thing at a time, plan very well, organize, pursue action, confronts with logic, rarely interrupts, stick to facts, truth, and limited body language. On the other hand, the multi-active group 
(included Saudi culture) are people who are emotional, display feelings, talk most the time, do many things at once, confront emotionally, good excuses, feelings before facts, flexible truth, often interrupts and unlimited body language (Cuco, 2015). The data analysis support this segmentation with its characters. Contrary to expectations, it did not support the point that the multi-active group (Saudi people) are emotional and display feelings, because the study sample (American participants) relied more on emotional techniques and showing their feelings than the Saudi participants.

\section{Findings}

This study has discussed three connected objectives. The first objective was to examine McGuire's model of persuasion and how it was applied on Shark Tanks' participants in both versions (American and Saudi version). The second objective was to determine the verbal and nonverbal techniques used by the participants. The third objective was to identify the linguistic and nonlinguistic differences between the two cultures (American and Saudi).

The findings revealed that McGuire's persuasion model was fully implemented by two out of four American participants, while only one out of four in the Saudi version applied the model in its six steps. This means that the McGuire's model has been fully implemented by fifty percent in the American version, and by only twenty five percent in the Saudi version. Interestingly, the supportive techniques could eventually lead to achieve the persuasion process.

As expected, many persuasive techniques were used by the participants in one position. These techniques include verbal techniques (tone, rhetorical questions, repetition, weasel words, jargon, slogan, alliteration, connotation, metaphor, simile, and statistic), non-verbal techniques (hand pointing, moving, eye brows movement, eye contact, smiling, humor, enthusiasm, self-confidence), and supportive techniques which are neither verbal nor nonverbal like giving samples. The findings revealed that the verbal techniques were more implemented by the American participants, and the nonverbal techniques were more implemented by the Saudis.

Table 5. Summarizes the major research findings

\begin{tabular}{|l|l|}
\hline American culture & Saudi culture \\
\hline - $50 \%$ application of McGuire's model & - $25 \%$ application of McGuire's model \\
- Low context meaning (messaging in & - High context meaning (meaning in \\
meaning) & \\
- Direct speech (to the point and clear) & - Indirect speech (ambiguous) \\
- Linear themes (One theme; organized & - Non-Linear themes (multi themes; \\
- with beginning and end) & - not organized) \\
- Vormal language & - Informal language \\
- Displays feelings - & - Nonverbal techniques \\
- Creative thinking - & - Simi conceals feelings \\
\hline
\end{tabular}


Moreover, the techniques of persuasion are not specific to one culture, rather, it is used in both cultures. If persuasion techniques are found to be somewhat similar among these two cultures, one can be greater in using these techniques with some differences according to the culture. In addition, culture has an influential role on the style of persuasion. This have led to the fact that the characteristics of the Americans' style of persuasion differ from those of the Saudis.

\section{Conclusion}

This study has raised many questions in need of further investigation. Hence, the researcher recommend further research should be undertaken as follow:

- A larger sample size is needed to validate and confirm the findings of this study.

- Research is needed to determine and study turn-taking processes in Shark Tank show.

- Future studies on the current topic (persuasion) are recommended to verify the McGuire theory in other TV shows.

\section{References}

Al-Khatib, M. A. (1994). A sociolinguistic view of the language of persuasion in Jordanian society. Language, culture and curriculum, 7(2), 161-174

Alshreef, Ruba. (2017). Shark Tank Season 6 Episode 14 (video file). Retrieved from https://www.youtube.com/watch?v=dXQiE-f9RuM\&t=2230s

Arakelyan, R. (2016). Language as an Influential Tool for Persuasion. Armenian Folia Anglistika, 1(15), 39

Berg, B. L. (2014). Qualitative Research Methods for the Social Sciences. 8th Edition, Pearson Education, Boston.

Blankenship, K. L., \& Craig, T. Y. (2011). Language Use and Persuasion: Multiple Roles for Linguistic Styles. Social and Personality Psychology Compass, 5(4), 194-205. https://doi.org/10.1111/j.1751-9004.2011.00344.x

Burgoon, M., \& Miller, G. R. (1985). An expectancy interpretation of language and persuasion. In H. Giles \& R. N. St. Clair (Eds.), Recent advances in language communication and social psychology (pp. 199-229). London, United Kingdom: Lawrence Erlbaum.

Crossculture.com. (2019). The Lewis Model - Dimensions of Behaviour | Cross Culture. [online] Available at https://www.crossculture.com/the-lewis-model-dimensions-of-behaviour/ [Accessed 29 Jul. 2019].

Dahl, S. (2007). McGuire's 6 step model. Retrieved from 
w6-https://www.slideshare.net/stephan/mkt4025

Jaradat, M. M., \& Abdel Haq, F. (1999). Strategies of persuasion used in Arabic among Jordanians: a sociolinguistic study (Doctoral dissertation, Yarmouk University)

Kirkbie Kendal School. (2012). Reality TV. Retrieved from 14314019-tv-https://www.slideshare.net/kksmedia/reality

Kolodziejczyk, A. M., \& Bosacki, S. L. (2016). Young-school-aged children's use of direct and indirect persuasion: Role of intentionality understanding. Psychology of Language and Communication, 20(3), 292-315.

Orji, M. Reisinger, M. Busch, A. Dijkstra, A. Stibe, M. Tscheligi (eds.)

Perloff, R. M. (2003). The Dynamics of Persuasion: Communication and Attitudes in the Twenty-First Century. UK: Lawrence Erlbaum Publishing.

Proceedings of the Personalization in Persuasive Technology Workshop, Persuasive

References of the Episodes:

Rotana, K. (2019). Al Hawamir Show, Second Season, episode 81(video file). Retrieved from https://www.youtube.com/watch?v=isdpENhvX98\&t=1924s

Simons, H. W. (1976). Persuasion: Understanding, practice, and analysis. Reading, Mass: Addison-Wesley Pub. Co.

Technology 2016, Salzburg, Austria, 05-04-2016.

Teh, I. (2011). William McGuire's Model of Persuasion. Retrieved from https://ivanteh-runningman.blogspot.com/2011/10/william-mcguires-model-of-persuasion-6.h tml 
Appendix A: Episode 14. Shark tank show (American version)

Participant (1)

\begin{tabular}{|c|c|c|c|}
\hline 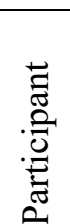 & TheSpeechEvent & $\begin{array}{l}\text { Verbaland } \\
\text { NonverbalTe } \\
\text { chniques }\end{array}$ & $\begin{array}{l}\text { Stepsofpers } \\
\text { uasion }\end{array}$ \\
\hline & $\begin{array}{l}\text { - We are two moms from Portland,Oregon and together we created } \\
\text { strategy and great baking company. } \\
\text {-Baking at homeIt's a very flawed production right you either have } \\
\text { that mystery bag of mix or that questionable tube of dough. } \\
\text {-Alternatively you can spend hours upon hours baking from } \\
\text { scratch at home who has the time and money for that right! } \\
\text {-Since there currently is no good option on the market to make } \\
\text { delicious homemade baked cookies so we created the cookie cake } \\
\text {-Cookie cake home baking easy and fun. } \\
\text {-So you have to do is supply the butter in the egg } \\
\text {-And we provide therest. } \\
\text {-And they tasteAmazing } \\
\text {-So sharks who is excited about the cookie kit it wants to jump in } \\
\text { this cookie jar by that. } \\
\text { Letusshowyou- } \\
\text { We packaged every single one of those ingredients by hand we still } \\
\text { hand label each one of those bags. } \\
\text {-All these things are what make our cookies better } \\
\text {-Um I had this bad experience baking with my children, and I have } \\
\text { this go- getter neighbor. } \\
\text {-when I had my first child I decided I just wasn't gonna put in } \\
\text { eighteen } \\
\text { hours for somebody else with no long- term payoff so I always } \\
\text { work. I'm the hardest worker. } \\
\text {-We are working so hard } \\
\text {-I honestly was raised by a single mom that struggled with drug } \\
\text { addiction or her whole life, and I worked my way out, I am sorry. } \\
\text {-That's what actually gave me my motivation to be where I am isn't } \\
\text { from seeing my mother who's made a lot of bad decisions, I put us } \\
\text { in a lot of bad situations, and so it's been my motivation to never } \\
\text { go through that. } \\
\text {-And we did it office we believe in the product, we believe in the } \\
\text { business. }\end{array}$ & $\begin{array}{l}\text {-Simultaneous } \\
\text {-Raising eye brows } \\
\text {-Rhetorical questions } \\
\text {-Using hands } \\
\text {-Repetition } \\
\text {-moving } \\
\text {-Smiling } \\
\text {-Tone } \\
\text {-Eye movement } \\
\text {-Tasting the product } \\
\text { by the } \\
\text { judgments(cookies) } \\
\text { Eyemovement- } \\
\text {-Argument } \\
\text {-Self-confidence } \\
\text {-Enthusiasm } \\
\text {-Sharing sad } \\
\text { emotions(crying) } \\
\text {-Showingsadness } \\
\text {-Humor }\end{array}$ & 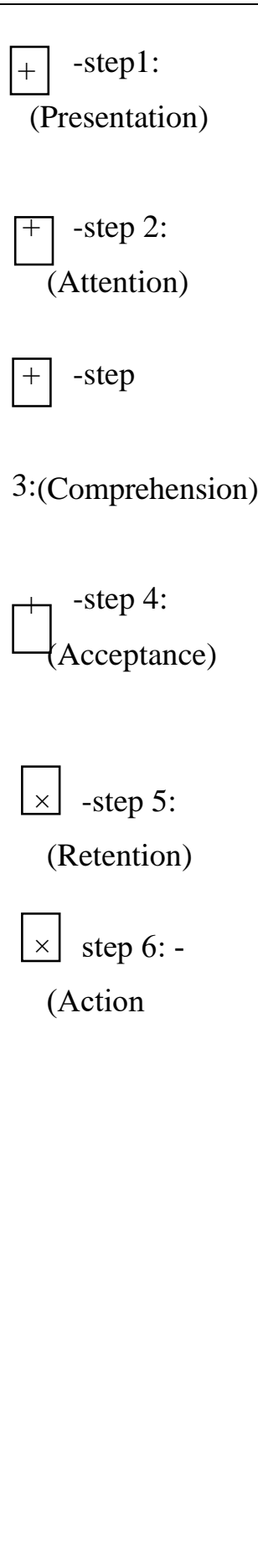 \\
\hline
\end{tabular}




\begin{tabular}{|c|c|c|c|}
\hline . & TheSpeechEvent & $\begin{array}{l}\text { Verbaland } \\
\text { NonverbalTe } \\
\text { chniques }\end{array}$ & $\begin{array}{l}\text { Stepsofpers } \\
\text { uasion }\end{array}$ \\
\hline & $\begin{array}{l}\text {-Sharks there are all kinds of portable drinking containers } \\
\text { that make our lives } \\
\text { easier.-The problem is they develop stains and odors easily } \\
\text { and the typical methods for cleaning them, just don't work } \\
\text { well. } \\
\text {-Dishwashers can't spray into narrow openings and many } \\
\text { drinking containers aren't dishwasher safe. } \\
\text {-We were frustrated by the lack of suitable methods to clean } \\
\text { our portable drink where we were looking for a solution that } \\
\text { was easy to use safe and effective. That's why we created } \\
\text { Bottle brite. } \\
\text {-Bottle brite is an effervescent cleaning tabletthat is amazing } \\
\text { at removing stains and odors for portable drink ware and it's } \\
\text { so easy to use. } \\
\text {-Simply fill your bottle with waterdrop in a bottle right tablet } \\
\text { and let it go to work then discard this solution give it a quick } \\
\text { rinse and your bottle is fresh and clean. } \\
\text {-We need your expertise in getting our unique products into } \\
\text { the hands of consumers. } \\
\text {-So who would like to join us in solving the dirty bottle } \\
\text { dilemma? } \\
\text {-I think the biggest difference between it and something like } \\
\text { Efferdent is this as all natural } \\
\text {-I think a lot of people give a damn } \\
\text {-I finished that ride that day pulled up to the trailhead and } \\
\text { said to Justin this thing tastes disgusting, cuz they're } \\
\text { impossible to clean so we had that issue I said to Justin I'm } \\
\text { leaving a healthy lifestyle, and I'm dumping bleach in here in } \\
\text { a now it tastes like a swimming pool, and I'm killing myself. } \\
\text { - If you were to invest with usI'd be completely open-minded } \\
\text { to any idea you had and what we should do with that money. } \\
\text {-We have a passion for this product. }\end{array}$ & $\begin{array}{l}\text {-Experience the } \\
\text { product } \\
\text {-Eye movement } \\
\text {-Smiling } \\
\text {-Giving samples } \\
\text {-Weasel words } \\
\text {-Anecdote } \\
\text {-Enthusiasm } \\
\text {-Passion }\end{array}$ & 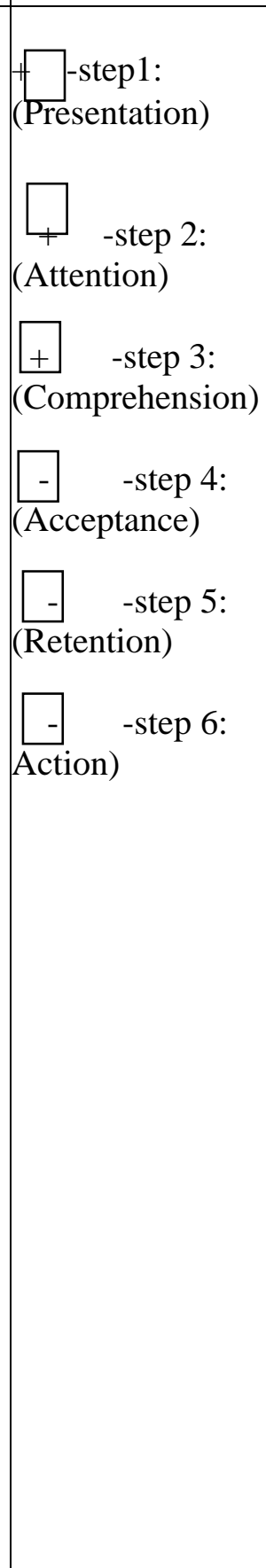 \\
\hline
\end{tabular}




\begin{tabular}{|c|c|c|c|}
\hline . & TheSpeechEvent & $\begin{array}{l}\text { Verbaland } \\
\text { NonverbalTe } \\
\text { chniques }\end{array}$ & $\begin{array}{l}\text { ofpersSteps } \\
\text { uasion }\end{array}$ \\
\hline & $\begin{array}{l}\text {-I am the financial officer of best pack } \\
\text {-I am the official licensee of the best pack } \\
\text {-Best-best facts was invented by my daughter when she was } \\
\text { in sixth grade her teacher gave our science project. Find a } \\
\text { problem come up with a solution. } \\
\text {-I never seen a product like this before. } \\
\text {-She created a new backpack. That's more } \\
\text { comfortableconvenient and stylish. } \\
\text {-Introducing best pack it's the best pack combination his } \\
\text { functional design helps distribute the weight. } \\
\text {-I've been in the backpack business, but over } 30 \text { years and } \\
\text { I've never seen a product like this before. } \\
\text {-Remember you could put important stuff up front like your } \\
\text { money! } \\
\text {-Okay, sharks, who wants to start putting money in your front } \\
\text { pockets? } \\
\text {-I make six and a half percent royalty } \\
\text {-In seventy five stores } \\
\text {-After my daughter had invented it she won her sixth grade } \\
\text {-ience class contest then another contest called million } \\
\text { weight. }\end{array}$ & $\begin{array}{l}\text {-Tone } \\
\text {-Giving samples } \\
\text {-Weasel words } \\
\text {-Eye movement and } \\
\text { raising eye brows }\end{array}$ & 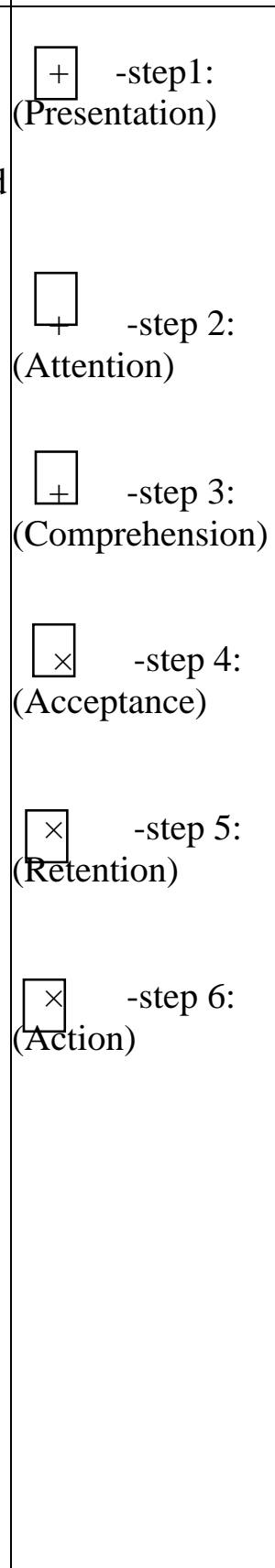 \\
\hline
\end{tabular}




\begin{tabular}{|c|c|c|c|}
\hline 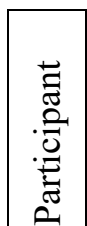 & eSpeechEventTh & $\begin{array}{l}\text { Verbaland } \\
\text { NonverbalTe } \\
\text { chniques }\end{array}$ & $\begin{array}{l}\text { Stepsofpers } \\
\text { uasion }\end{array}$ \\
\hline & $\begin{array}{l}\text {-Hang on to your notes Sharks because we're about to show } \\
\text { you where you can stick it. } \\
\text {-We design and manufacture wearable fabric sticker } \\
\text { accessories thatInstant fun to any occasion like our flagship } \\
\text { product the sticky tie. } \\
\text {-They are reusable they won't tear or lose their shape plain } \\
\text { white t-shirt, They are reusable they won't tear or lose their } \\
\text { shape plain white t-shirt. } \\
\text {-Party shirt! } \\
\text {-And if you happen to spill something on them they could be } \\
\text { wiped clean and worn again and again and again. } \\
\text {-Sharks we have some samples that we put together just for } \\
\text { you. } \\
\text {-Because we made a conscious decision at the end of the year } \\
\text { to slow our engines down and figure it out } \\
\text {-Because it is something that you can reuse over and over } \\
\text { again } \\
\text {-And then you are gonna have something that in the end is } \\
\text { peeling off not staying stuck } \\
\text {-We are having so much fun in doing it } \\
\text {-Well I feel really great sadness right now because we really } \\
\text { do love this, we put a lot } \\
\text { into it. }\end{array}$ & $\begin{array}{l}\text {-Using hands } \\
\text {-Raising eye brows } \\
\text {-Enthusiasm } \\
\text {-Sharing sad } \\
\text { emotions }\end{array}$ & 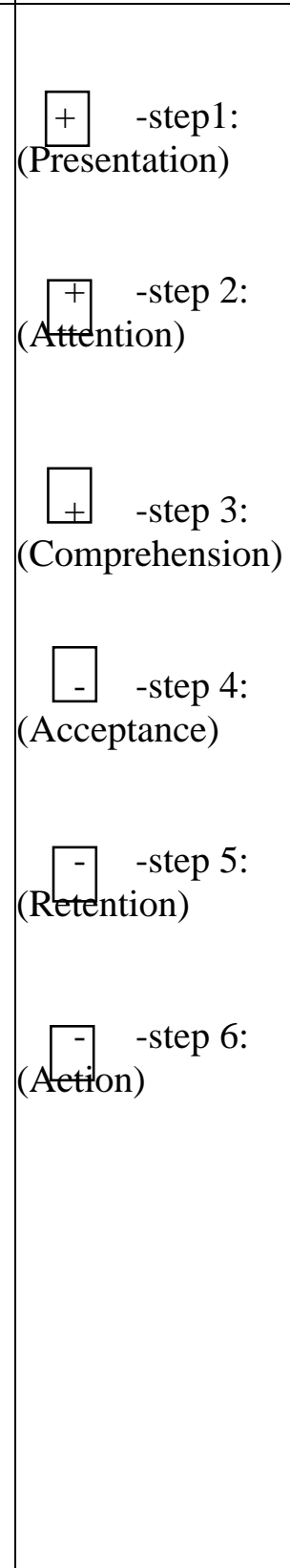 \\
\hline
\end{tabular}


Appendix B: Episode 14. Shark tank show ( Saudi version)

Participant (1)

\begin{tabular}{|c|c|c|c|}
\hline 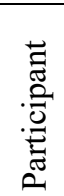 & TheSpeechEvent & $\begin{array}{l}\text { Verbaland } \\
\text { NonverbalTec } \\
\text { hniques }\end{array}$ & $\begin{array}{l}\text { Stepsofpersu } \\
\text { asion }\end{array}$ \\
\hline & 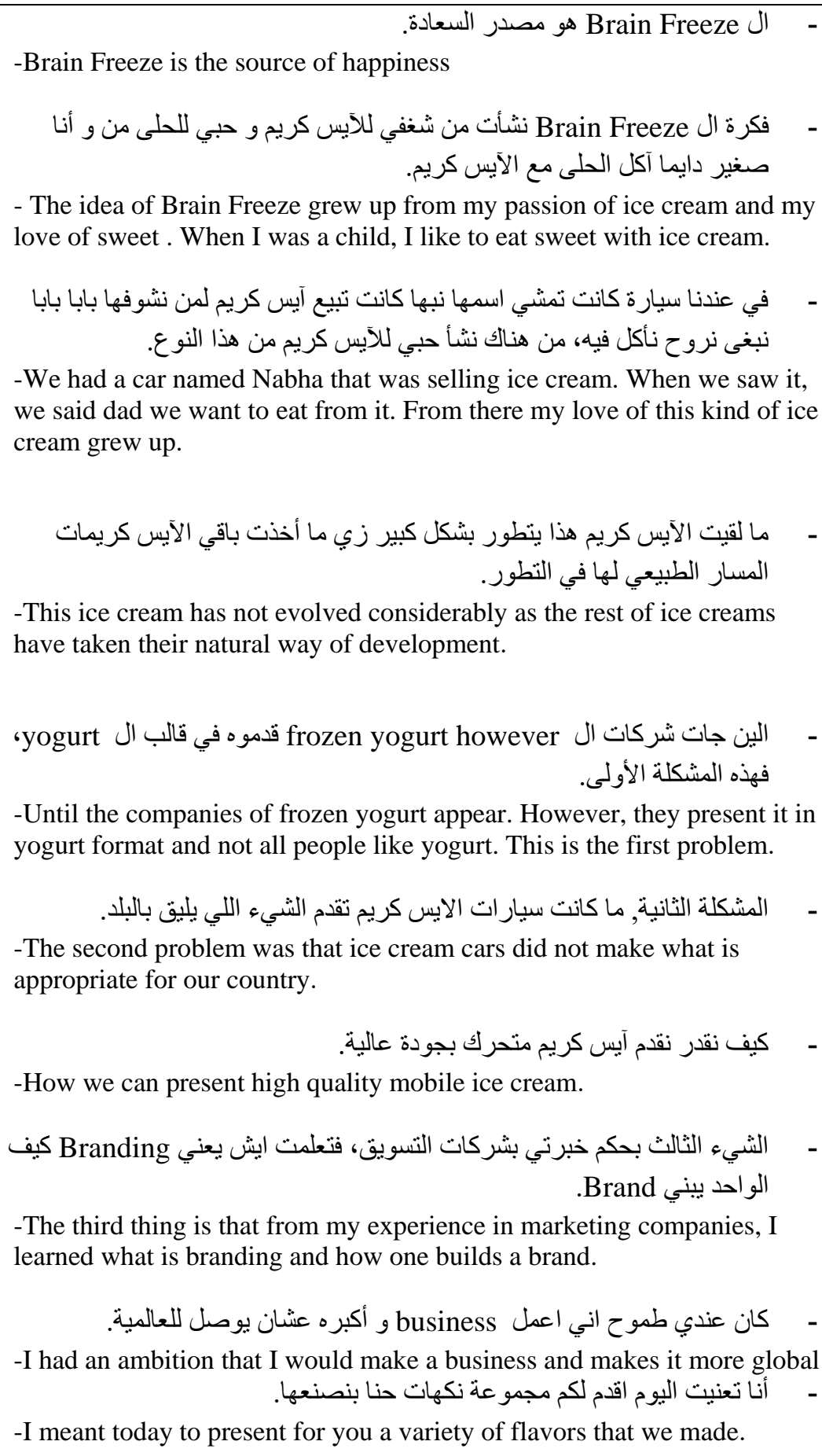 & $\begin{array}{l}\text {-Slogan } \\
\text {-Repetition } \\
\text {-Smiling } \\
\text {-Eye movement } \\
\text {-Eye brows movement } \\
\text { andweasel words } \\
\text {-Reasoning } \\
\text {-Hands movement } \\
\text {-Self confidence } \\
\text {-Enthusiasm } \\
\text {-Tasting the product } \\
\text { (ice cream) } \\
\text {-Moving freely } \\
\text {-Jargon } \\
\text {-Own experience } \\
\text {-Enthusiasm } \\
\text {-Sharing emotions }\end{array}$ & 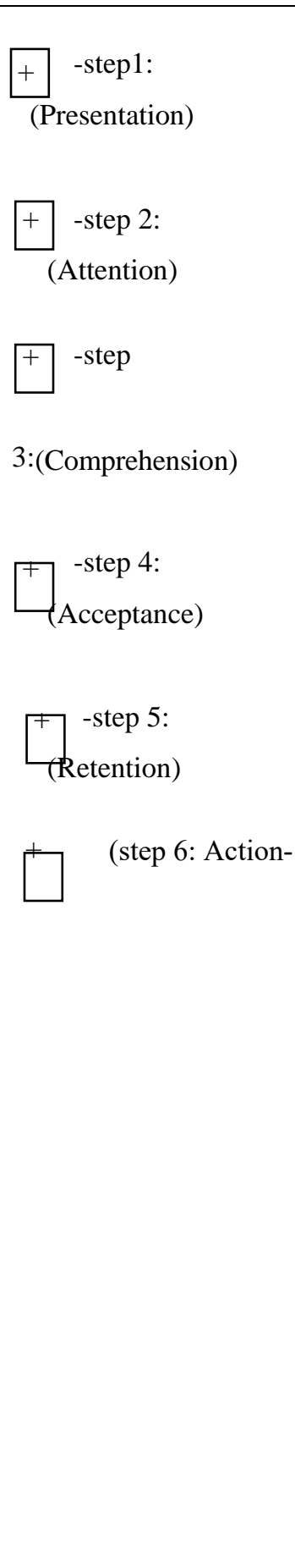 \\
\hline
\end{tabular}


-I learned how to do it from Italy.

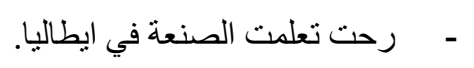

$$
\text { - اللي عندكم فيها Innovation وذا الثيء اللي يميزنا. }
$$

-These flavors have innovation and this is what distinguishes us.

$$
\text { - - هذي النكهه ذقتها في ديزني وتعرفت على العالم هذا من خلالها. }
$$

-I taste this flavor in Disney and I knew this world through it.

$$
\begin{aligned}
& \text { - متعثت أكثر و عرفت كيف اسوي آيس كريم zero in sugar و هذا الثي ماني } \\
& \text { قادره لسا أطلعه ألني محتاجة دعمكم. }
\end{aligned}
$$

-I learned more and knew how to make ice cream zero in sugar and zero in fat. But, I cannot produce this thing because I need your support.

- أنا تركت وظيفتي عشان أسس هذا ال business، وصبرت لين اللحظة هذي

$$
\text { عشان أقدم شيء يليق. }
$$

-I left my job to establish this business,I have been waiting for moment to make something worthwhile.this 


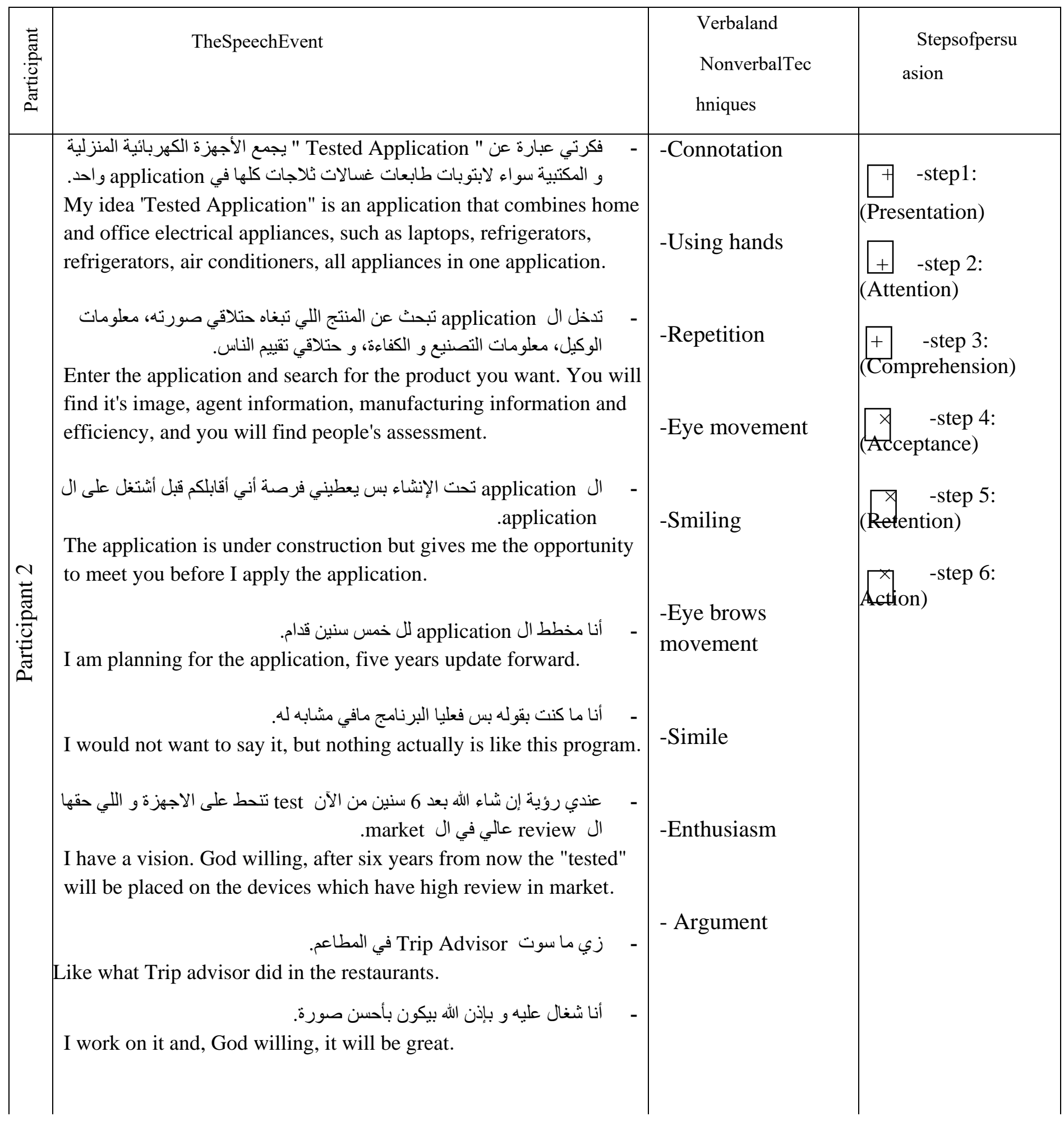


- الميزة التنافسية ان يمكن تكوني بالمحل نفسه تشوفين الجهاز اللي قدامك ما تعتمدي على كلام البياع.

The competitive advantage is that if you are in a store, you can see the device that is front you and do not depend on the seller's words. 


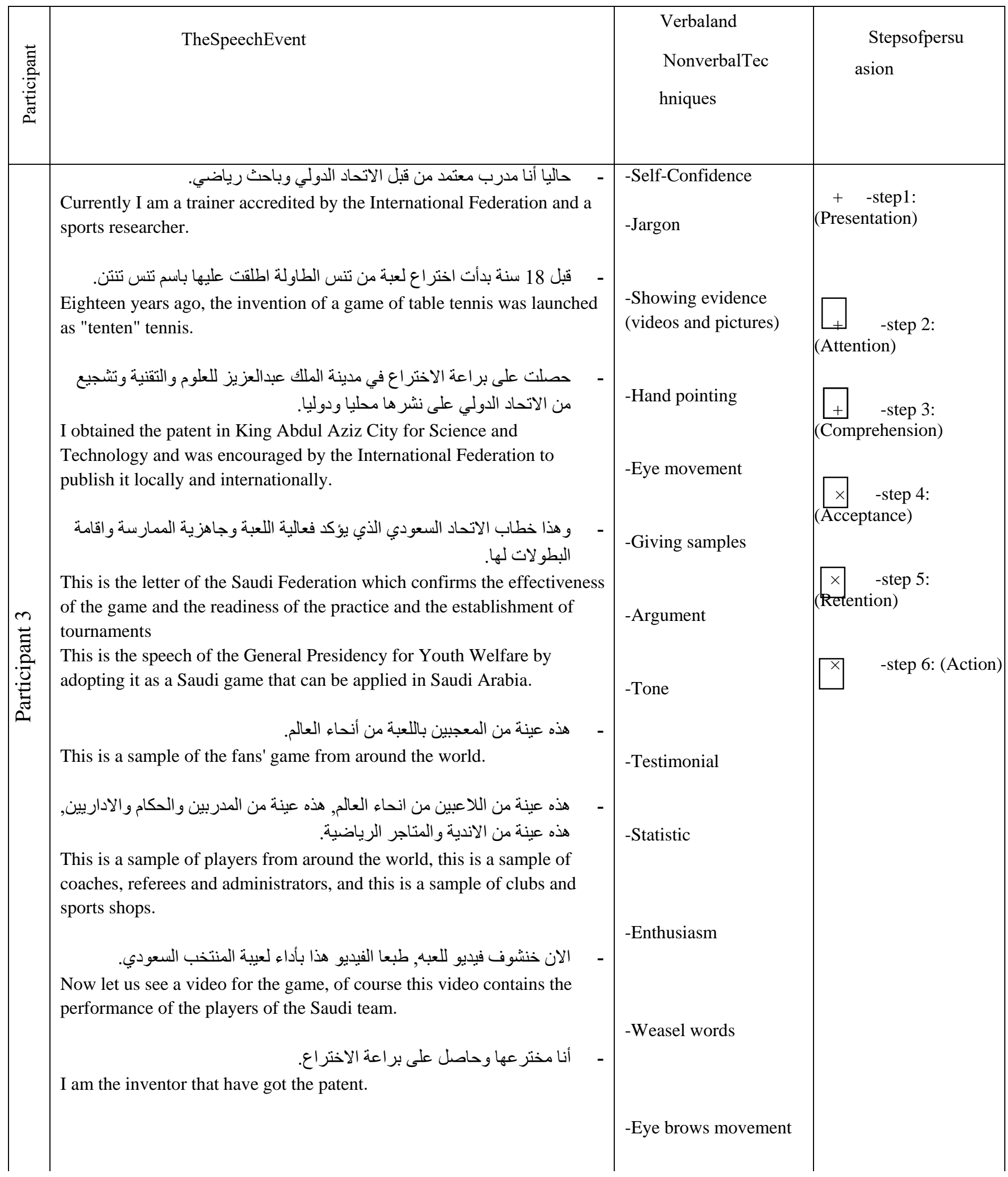




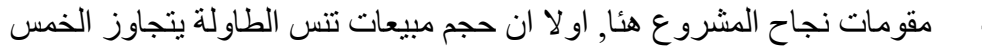

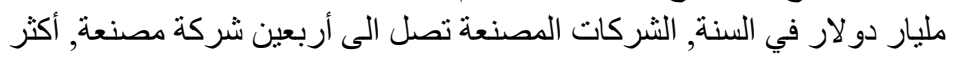

$$
\begin{aligned}
& \text { من } 13 \text { منتج يباع. }
\end{aligned}
$$

The success of this project are, first, the size of table tennis sales exceeds five billion dollars a year. Manufacturers up to forty ones, more than thirteen products are sold.

$$
\text { مبيعات هذه الثركات. - مذهنة أنها تزيد من عدد اللاعبين وبزيادة عدد اللاعبين حتزداد }
$$

The advantage of this game is that it increase the number of players and by increasing the number of players, the sales of these companies will increase.

$$
\text { - بالنسبة لتنس الطاولة, الكثبر من اللاعبين اعجبو ا بهذه اللعبة و السبب أنها تعطي }
$$

For table tennis, a lot of players were impressed by this game because it give them a chance to participate.

$$
\text { ـالمعبين من أنحاء العالم شفتهم على الفيسبوك. }
$$

I saw fans from around the world on Face book. 
Participant (4)

\begin{tabular}{|c|c|c|c|}
\hline 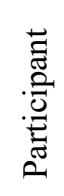 & TheSpeechEvent & $\begin{array}{l}\text { Verbaland } \\
\text { NonverbalTec } \\
\text { hniques }\end{array}$ & $\begin{array}{l}\text { Stepsofpersu } \\
\text { asion }\end{array}$ \\
\hline 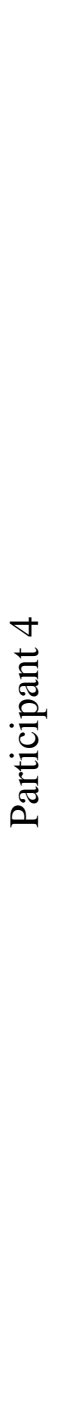 & 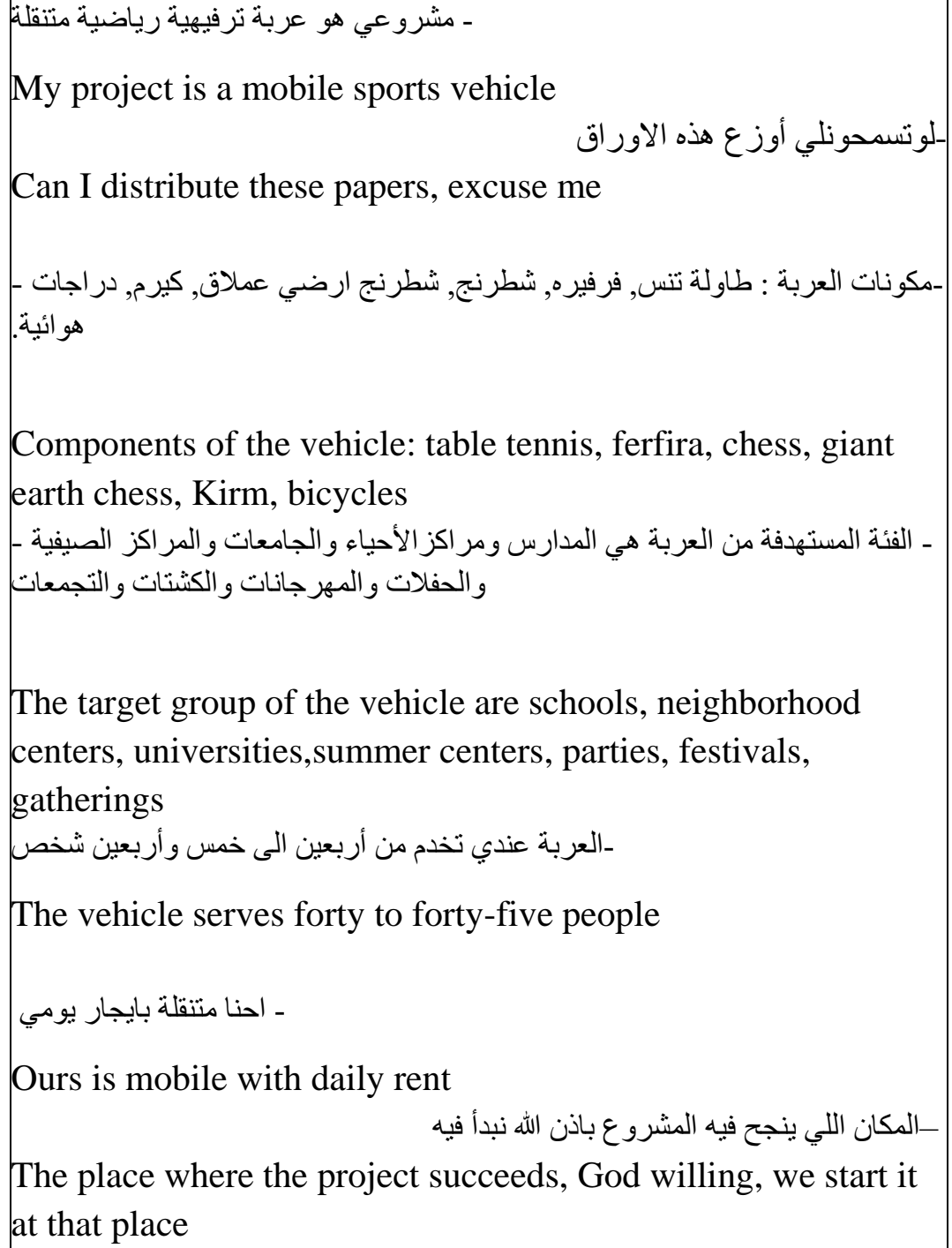 & $\begin{array}{l}\text {-Giving samples } \\
\text { (bulletins) } \\
\text {-Appearance of } \\
\text { product content }\end{array}$ & 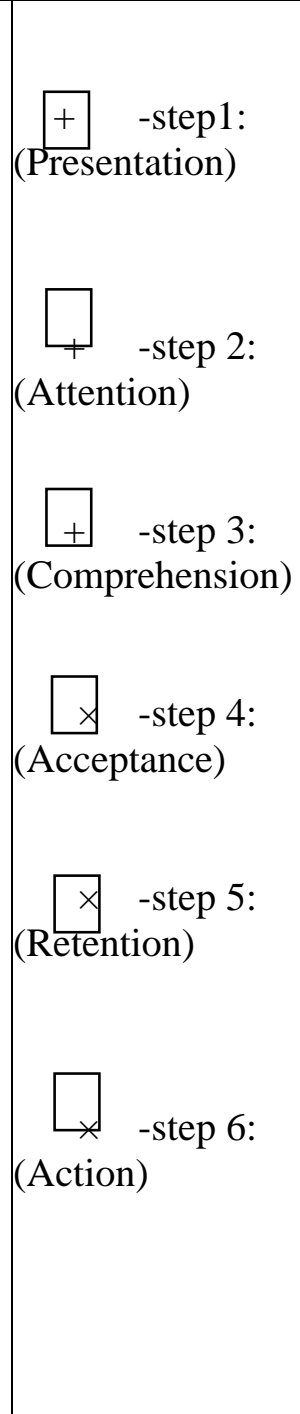 \\
\hline
\end{tabular}

\section{Copyright Disclaimer}

Copyright for this article is retained by the author(s), with first publication rights granted to the journal.

This is an open-access article distributed under the terms and conditions of the Creative Commons Attribution license (http://creativecommons.org/licenses/by/3.0/). 